tablished regular gatherings of international scholars from a wide variety of disciplines, the working reports of the first four meetings, translated from German, are included in this bibliography. Three of them, presumably written by Prof. W. Heissig, were once informally published bundled in a small booklet. The report of the fourth meeting 1961, written by Denis Sinor, appeared in the first regular volume of proceedings of the 1962 meeting; it is included here as well.

\title{
About This Bibliography
}

\section{Scope}

This bibliography contains the references to all articles and abstracts published until early 2017, as well as the articles of the 2014 Meeting in Kocaeli the proceedings of which hopefully will appear soon. References are presented in their original languages, so that Russian, German, Turkish and English (with a few French and Chinese contributions) share one common list. The sorting order follows the Latin alphabet, and contributions using the Cyrillic alphabet (besides Russian, there are also Tatar papers) appear in the sorting order of their romanizations, following the example of the proceedings of the $12^{\text {th }}$ Meeting in Berlin, German Democratic Republic, and later proceedings with a sizable Russian contribution. Chinese entries are treated in the same way, sorted by their pinyin romanization.

\section{Structure}

The bibliography itself is organized in three parts. In the first part, there is a list of all published proceedings and collections of abstracts, supplemented by a list of annual themes in alphabetical order of keywords. The second and largest part contains the references to articles and abstracts sorted alphabetically by author. The third part consists of a fairly exhaustive keyword index (in Latin and Cyrillic alphabets as well as Chinese) preceded by a list of co-authors.

The references of working reports, articles and abstracts (beginning on page 25) point to the list of proceedings (beginning on page 17). The reference year always indicates the year the meeting was held, not the year the proceedings were published. In some years, individual contributions were either published in instalments of a journal (e. g. $1980 \mathrm{~A}, 1980 \mathrm{~B}$ and $1980 \mathrm{C}$ ), in multi-volume collections (as in $1986 \mathrm{~A}$ and $1986 \mathrm{~B}$ ) or in different journals, depending on the language (1986 C and 1986 D). In these cases, the letters A to D preceding the page number in the bibliographical reference entry indicate which publication of that year is to be consulted.

\section{Note of Thanks}

In many ways, this bibliography is the fruit of a collective effort. First of all, there are the forefathers of Altaic studies who produced an impressive body of knowledge as the number of listed articles and abstracts (well over 1,500) demonstrates. Collecting and arranging these fruits of academic research into a single reference volume is not as straightforward as usual due to publications in a variety of formats and languages. Without the tireless efforts of Hartmut Walravens and Barbara Kellner-Heinkele who unearthed so many treasures from their private collections, this bibliography would not have seen the light of day. The editor's translations of the working reports of 
the first years were reviewed by Christine Bell. Barbara Kellner-Heinkele also helped with proofreading and the selection of suitable Turkish keywords for the index. Gerd Winkelhane, of Klaus Schwarz Verlag, generously accepted this bibliography for print, and Mr. Jeep, his technical editor, shared much of his time and his profound knowledge of typography with me while steering me towards the optimal layout decisions. Ákos Bertalan Apatóczky and Hartmut Walravens steered my attention towards a number of orthographical variants or unconventional spellings of names. Fortunately, the publisher accepted the corrections at the last possible moment. Despite all these essential contributions, the responsibility for errors is solely mine.

May this bibliography help us appreciate the scholarly achievements of 60 years of the PIAC, and may it kindle new scientific exchange and research!

Oliver Corff, July 2017 
